\title{
ABREU, Caio Fernando. Poesias nunca lidas de Caio Fernando Abreu. Org. Letícia da Costa Chaplin e Márcia Ivana de Lima e Silva. Rio de Janeiro: Record, 2012.
}

\author{
Daniel de Oliveira Gomes \\ Unicentro
}

Um dos mais brilhantes escritores gaúchos, Caio Fernando Abreu - falecido jovem na década de noventa, tal como seu amigo Cazuza, em razão da Aids - vinha por décadas sendo observado pela crítica como um exímio contista, cronista, romancista, jornalista, etc... Contudo, muito raramente alguém mencionava algo sobre o fato de ele escrever ou não poesias. Isabella Marcatti, em artigo na revista Bravo!, lembrava que sua fluência capital estava no conto, porém, também, "de vez em quando, na poesia, sempre tentando impor à linguagem o ritmo da respiração vital”. Respiração esta que notamos agudamente em tudo que o autor fazia, visceralmente embebido de senso lírico, de sentimento.

Na época da morte de Caio Fernando Abreu, saiu uma matéria especial em $O$ Estado de São Paulo, na qual Lygia Fagundes Telles bem lembrava o "gesto poético" de Caio no modo como cuidava de suas roseiras, antes de falecer. "Em alguns dias, nos últimos tempos, quando não conseguia escrever, quando a cabeça não atendia aos seus apelos, ele ia para o jardim, cuidar das rosas. Ia cuidar da vida: tirar da terra a vida, e o Caio morrendo" . De modo geral, a poesia que Caio escrevia foi encarada como um passatempo, o "outro lado" da vida, do mesmo modo como o gesto poético de que trata Lygia Fagundes Telles se refere a um simples passatempo do autor, no final da vida. A discussão sobre esta ontologia do poeta que nos surge é aqui estéril, pois hoje passamos a notar que seu zeloso gesto poético ia muito além do hobby, do cultivo de rosas, ou da jardinagem da palavra guardada a sete chaves. A poesia foi muito mais que um passatempo, talvez aquilo que para ele era a dimensão da própria escritura, um "jeito de viver”, tal como teria dito em uma carta à escritora Hilda Hilst.

As poesias de Caio estiveram, então, por décadas arquivadas como manuscritos, alguns demasiadamente rasurados, muitos deles corroídos pelo tempo e pelo desinteresse geral. A exceção talvez seja a tese doutoral de Letícia Costa Chaplin, defendida em 2010, na UFRGS, que, sob a mirada da Crítica Genética, reunia ousadamente suas poesias, em um esforço, inclusive interpretativo, de decifração dos rabiscados originais. Iniciativa que resultou, enfim, em uma coletânea de seus poemas a partir de (por um 
lado) análises de diários, anotações, materiais que estavam com a família do autor e (por outro lado) da coleta de mais de 90 poemas, antes encontrados apenas em arquivo especial sob a guarda do Instituto de Letras da UFRGS.

Felizmente, o resultado mais aguardado desta pesquisa acabou saindo do acastelado âmbito acadêmico, com a publicação, pela editora Record, de uma coletânea poética de Caio Fernando Abreu em fins de 2012. Esta coletânea vem a ser, provavelmente, fruto da tese em questão, visto que se apresenta organizada pelas próprias professoras Márcia Ivana de Lima e Silva (orientadora da tese) e Letícia da Costa Chaplin (pesquisadora).

É interessante observar como o título de tal coletânea de cento e dezesseis poemas se oferece: Poesias nunca publicadas de Caio Fernando Abreu. Pensando bem, não se trata apenas de poemas inéditos de Abreu, falamos de uma face inédita do autor. Veja que uma coisa é localizar um arquivo inédito de um gênero que determinado autor já escrevia, a outra é tornar pública uma nova modalidade de produção de um autor. Trata-se de um poeta que brota sob a assinatura-botão de uma roseira renomada, um poeta em flor que nasce inadiável, pois, em suma, sempre existiu neste jardim. Entretanto, como serão "nunca publicadas" tais poesias se são, neste exato momento, precisamente viáveis à leitura, ao cultivo? Ou seja, quando alguma coisa é desenterrada, qual é a pretensão em jogo de se intitular como obras "nunca publicadas"? Apesar desta incoerência, cremos que as autoras foram felizes neste título que aplaca a culpabilidade possível.

As autoras mostram assim que, possivelmente, o que está mais em questão vem a ser uma consciência de que a divulgação destas poesias não pode se propor a completar uma lacuna para a fortuna crítica do autor. Muito menos afirmar que nesta obra havia um vazio que era o gênero poético. Esta publicação, provavelmente, não finalizará de forma cabal uma obra, ou tentará transformar Abreu em poeta da noite para o dia; ao contrário, ela abre a possibilidade autoral de vermos outros corais onde o marinheiro que já conhecemos se ancorou em suas viagens. Como cada um irá ler e acatar estas poesias é outra história. Este marinheiro já existia e estes mares também. Assim, põe-se em relevo a parcela de uma obra que não passou pela intenção do autor tornar pública, mas que acaba sendo de grande importância para, ao menos, degustarmos um outro movimento de sua escrita. Como diriam seus versos, da década de 90: "Por que mares andarás, marinheiro/ ancorado entre corais?” E outro poema responderia: "e todos os dias/ trazer a tona meu melhor rosto/ para que os outros não se assustem/ para que os outros não se espantem/ para que eu não me dane e sangre”. Notamos que os rostos, as faces, de Caio Fernando Abreu são ainda mais numerosos e vivos do que pensávamos, por mais que seu estilo poético lembre muito de sua prosa.

O leitor tem a faca e o queijo nas mãos para se surpreender com a face poética do autor, mesmo considerando que efetivamente houve inter- 
venções em seus manuscritos inacabados, pois alguns apresentavam várias versões diferentes, tal como nos contam as autoras. Voltando à década de 60 - o livro vem dividido por capítulos que marcam as décadas de sua produção poética - achamos um poema que diz: "Muitos mares andei/ outros pensei./ E nos pensares muito mais vivi/ que nos andares/ pausados estes. Compassados.” Ao que se pode concluir, a poesia era esse exercício de andarilho, essa busca de um modo diferente de sentir seu próprio pensamento, algo muito íntimo para ele. "E todos os dias/ todos os dias/ controlar o ridículo/ para não confessar amores inconfessáveis”. Porém, a sua prosa também nunca deixou de se revelar intimista, bem sabemos, sob temas dos mais intensos, tais como a solidão, o amor, o desencanto, a insanidade de uma era marcada pela transversalidade de poderes, sentimentos etc. Provavelmente, não foi por timidez que Caio não publicou poesias em vida, dada a tendência tão combativa e em nada acanhada do autor que conhecíamos.

Agora, passamos com estes poemas a distinguir um outro lado do escritor, no sentido de uma "imagem de isolamento" que muitos destes versos nos apresentam e que, como diz a introdução das organizadoras, era próprio de muitos momentos do autor, mesmo que poucos saibam. Pois ele, não raro, isolava-se em seu quarto, trancando-se para o retraimento de escrever, o que significativamente terá resultado em algumas dessas poesias que, agora, temos a oportunidade de tomar ciência. O encanto de, inclusive, perguntarmos: mas, ora, como tais poesias estão sendo publicadas apenas agora? Quem adiou o poeta? Mas o poeta já existia, sempre existiu, era inadiável, desde os anos 60 já estava lá, aqui, dizendo "não me guardes" (em poema impresso no Jornal Cruzeiro do Sul), sempre se autoconheceu, apenas não deu as caras em versos. Mas ele habitou o poético sempre; quem não existia era o leitor de seus poemas. "Ninguém me tira/ a certeza de te ter habitado". Veja-se tanto a dimensão poética, entendida em prosa, que o mesmo fazia abrolhar na lírica de seu estilo, suas confabulações ácidas, com tão grande desapego e por vezes humor, niilismo, "triste, triste viver num tempo sem deuses".

O próprio de Caio era jamais se esquivar. Em matéria de poesia, nunca se subtraiu, mesmo não tendo publicado em vida seus poemas. "Escuta:/ não sei escrever poemas/ quando estou dentro dum poema/ vivo e sem palavras/ mas se penso em te dizer/ aqui agora assim/ faço rimas formas talvez mortas/ porque não me esquivo.”

Tanta franqueza poética - e ao mesmo tempo o extremo senso de inoperância, a inventividade musical, a busca da fugacidade extrema e, simultaneamente, a honestidade do encontro verdadeiro. "Quero ficar no meu canto./ Me deixe só no meu canto/ tonto, zonzo, pronto.” Enfim, características ambivalentes com as quais já nos defrontamos em sua escrita em prosa e que eram, talvez, qualidades mais próprias da dimensão poética mesmo que não as percebêssemos ali de imediato. E muitas 
vezes até mesmo a tendência ao desapego político e envolvimento mais genuinamente etopoiético com a linguagem (crença implícita que em todo seu exercício estético estava também o ético). Tanto assim que parte da própria crítica do autor não consegue até hoje, muitas vezes, compreender a sua dimensão apolítica e nietzschiana, por vezes ressalvando teimosamente uma força contra-moralizante que nos guia exaustivamente à repressão no Brasil, de contexto militar. Mas, nestas poesias, o antagonismo social está ainda mais aparente. Sua preocupação é ficar no seu canto. Cantar. O espírito do poeta arrancado da estufa, do quarto, para a vitrine. Ainda mais aparente está o outro lado, um lado íntimo que, apenas ao ler, notamos que era preciso inadiavelmente dar a conhecer em Caio. Um sobrevivente da poesia: sobrevivente que aparece, de repente. Embora não publicado, eis um poeta que reconhecemos na leitura - inadiável, portanto. "Pois um sobrevivente/ nunca imaginou que pudesse um dia/ virar sobrevivente de um tempo/ e de si mesmo/ mas virou".

\section{Referências}

ABREU, Caio Fernando. Poesias nunca lidas de Caio Fernando Abreu. Org. Letícia da Costa Chaplin e Márcia Ivana de Lima e Silva. Rio de Janeiro: Record, 2012.

CAIO Fernando Abreu deixa inéditos e projetos. Folha de São Paulo. São Paulo, p. 5, 28 fev. 1996.

CHAPLIN, Letícia da Costa. De ausências \& Distâncias te construo: a poesia de Caio Fernando Abreu. Tese de Doutorado em Letras. Porto Alegre: UFRGS, 2010.

LEAL, Bruno. Caio Fernando Abreu, a metrópole e a paixão do estrangeiro: contos, identidade e sexualidade em trânsito. São Paulo: Annablume, 2002.

MARCATTI, Isabella. Leia esta canção. Bravo! Revista crítica de arte, São Paulo, SP, ano 9, n. 102, p. 57, fev. de 2006. 